\title{
Investigating the Prevalence of Shigella Species and Their Antibiotic Resistance Pattern in Children With Acute Diarrhea Referred to Selected Hospitals in Tehran, Iran
}

\author{
Peyman Avakh Majalan', Abbas Hajizade ${ }^{1 *}$, Shahram Nazarian', Mohammad Reza Pourmand ${ }^{2}$, Kiana Amiri \\ Siyavoshani ${ }^{3}$
}

${ }^{1}$ Biology Research Center, Faculty of Basic Sciences, Imam Hossain Comprehensive University, Tehran, Iran ${ }^{2}$ Department of Pathobiology, School of Public Health, Tehran University of Medical Sciences, Tehran, Iran ${ }^{3}$ Department of Clinical Microbiology, Tehran University of Medical Sciences, Tehran, Iran

Corresponding Author: Abbas Hajizade, Biology Research Center, Faculty of Basic Sciences, Imam Hossain Comprehensive University, Tehran, Iran. Tel: +98-9127239829, Email: Abbashajizade@gmail.com

Received March 12, 2018; Revised March 28, 2018; Accepted April 9, 2018; Online Published June 20, 2018

\begin{abstract}
Introduction: Shigellosis is a major health problem, especially in developing countries and in children under 5 years of age. The prevalence of Shigella species in a region can be considered as an indicator for hygiene level of that region. Due to the lack of an efficient vaccine, antibiotic therapy is the main strategy to combat the disease. In this study, the prevalence of the Shigella species and their antibiotic resistant pattern has been investigated.

Materials and Methods: A total of 300 diarrheal stool samples were collected from 4 different hospitals in Tehran during a period of 6 months June to November 2016. Bacterial identification and species discrimination was performed using biochemical and serotyping tests. Antibiotic resistance patterns of isolates were obtained using Bauer-Kirby method.

Results: $8.7 \%$ of all diarrheal cases were caused by Shigella species (5\% by Shigella sonnei and 3.7\% by Shigella flexneri). Antibiogram test revealed that the isolates were more sensitive or intermediate to ciprofloxacin $(92.3 \%)$, while most of the isolates were resistant to tetracycline.

Conclusions: The prevalence of Shigella species has changed in Tehran. Since antibiotics are the treatment of choice to combat these pathogens, also, because of the emergence of the antibiotic resistance Shigella strains, there is a need for regularly updated regional antibiotic sensitivity patterns of the pathogen to guide therapy.

Keywords: Shigella species, Antibiotic Sensitivity Pattern, Prevalence, Diarrhea

Citation: Avakh Majalan P, Hajizade A, Nazarian S, Pourmand MR, Amiri Siyavoshani K. Investigating the prevalence of Shigella species and their antibiotic resistance pattern in children with acute diarrhea referred to selected hospitals in Tehran, Iran. J Appl Biotechnol Rep. 2018;5(2):70-74. doi:10.29252/jabr.05.02.06.
\end{abstract}

\section{Introduction}

Caused by Shigella species, shigellosis is an infectious disease which is endemic in many developing countries. ${ }^{1}$ Annually, there are about 80 million cases of bloody diarrhea and 700000 deaths due to this infection. ${ }^{2}$ Children under 5 years old, elderly, and immunocompromised people are at a higher risk to this infection and develop more severe symptoms. ${ }^{3,4}$ The majority of the disease cases are seen in developing countries and it is due to the poor hygiene standards, poor water quality, etc. ${ }^{5}$

Four different species of Shigella genus can develop the disease, Shigella sonnei, Shigella dysenteriae, Shigella flexneri, and Shigella boydii. The incidence of the species is so different in various countries: while $S$. flexneri is the prevalence serogroup in developing countries, the most cases of the infection in developed countries are caused by $S$. sonnei. ${ }^{6,7}$ Since it is transmitted via fecal-oral rout in a low dose (1-500 organisms) and also via direct spread by person to person contact, the control of the infection is a great challenge. ${ }^{8,9}$

Shigella infection can cause different symptoms from a mild self-limiting diarrhea to severe dysentery associated with blood and mucus excretion, high fever, and cramps. ${ }^{10,11}$ Since there is no approved vaccine, despite all attempts, ${ }^{12-14}$ antibiotic therapy is the main strategy to combat the disease. Appropriate antibiotic therapy shortens the disease symptoms and prevents the life-threatening effects, also, it decreases the bacterial shedding in feces and, therefore, decreases the bacterial spread..$^{15}$ However, during recent decades, the indiscriminate use of antibiotics has led to the resistance of Shigella spp. to common antibiotics. ${ }^{16,17}$ Due to the self-limiting nature of the

Copyright (C) 2018 The Author(s). This is an open-access article distributed under the terms of the Creative Commons Attribution License (http:// creativecommons.org/licenses/by/4.0), which permits unrestricted use, distribution, and reproduction in any medium, provided the original work is properly cited. 
infection, the high risk of the emergence of drug resistance strains, and the costs of drugs, some physicians avoid the antibiotic administration. ${ }^{18}$ However, there is a convincingly logic in favor of empirical treatment of shigellosis in suspected patients. If the disease won't be treated, a child may be quite sick for several weeks or more and chronic diarrhea may be created. During prolonged illness, the risks for developing or worsening the disease, malnutrition, permanent disposal of microorganisms, and subsequent infection of family members will be increased. However, the resistance of the bacteria to common antibiotics has limited the use of these antimicrobial agents. Although it was thought that Shigella is sensitive to ceftriaxone, azithromycin, and quinolones, there are increasing number of reports which show the increase in multiple drug-resistancy of the bacterial strains in different parts of the world. In Iran, more than $90 \%$ of Shigella species are resistant to one or more antibiotics and about $87 \%$ of them are resistant to more than one antibiotic. ${ }^{19}$ Since shigellosis is the worldwide health problem and it is endemic in some regions of Iran, ${ }^{20}$ and also because of the importance of the determination of antibiotic resistant pattern of the bacteria in the selection of the proper treatment regimen, in the present study, the prevalence of Shigella species and also the antibiotic resistance pattern of them were investigated.

\section{Materials and Methods}

This is a hospital-based descriptive-analytic study based on stool samples of patients with diarrhea and fever diagnosed with colitis in four educational hospitals.

\section{Sample Collection}

Three hundred diarrhea samples were collected from four hospitals in Tehran, including Sina, Shariati, Imam Khomeini, and children medical center hospitals in a time period from June to November 2016. Sampling performed before antibiotic therapy and stool specimens were transported in Cary-Blair transport medium and carried to the microbiology laboratory for future analysis.

\section{Bacterial Culture and Identification}

Samples were firstly cultured on Xylose Lysine Deoxycholate (XLD) agar (Merck, Germany), Hekton enteric agar (Merck, Germany), and S-S agar (Merck, Germany) for 24 hours at $37^{\circ} \mathrm{C}$. Then, they were transferred to Muller-Hinton agar (Sigma, USA) for biochemical tests. Identification was performed by different biochemical tests, including Triple Sugar Iron (TSI) (Merck, Germany), lysine decarboxylase, SIM (Merck, Germany), MR-VP (methyl red, VogesProskauer), citrate utilization, and urea hydrolysis tests.

\section{Species Discrimination}

For discrimination of different Shigella species, ornithine decarboxylase, ONPG (o-nitrophenyle - $\beta$-D-galactosidase), manitole fermentation, and finally, serotyping tests was performed. Serotyping was done via the slide agglutination method using antisera (Bahar Afshan, Iran) against each species.
Antibiotic Resistance Investigation

Antibiotic resistance test was carried out using Bauer-Kirby method according to the US Clinical and Laboratory Standards Institute (CLSI). To do this, firstly, a bacterial suspension equivalent to $0.5 \mathrm{McF}$ arland Standard was prepared for all isolates. Using a sterile swab, the suspension was spread on a Muller-Hinton agar medium. After 15 minutes, antibiotic discs were placed on the media. The studied antibiotics were: ampicillin (AMP; $10 \mathrm{mg}$ ), tetracycline (TCN; $30 \mathrm{mg}$ ), ciprofloxacin (CIP; $5 \mathrm{mg}$ ), nalidixic acid (NAL; $30 \mathrm{mg}$ ), gentamycin (GEN; $25 \mathrm{mg}$ ), sulfamethoxazole/trimethoprim (SXT; $25 \mathrm{mg}$ ), ceftriaxone (CAX, $30 \mathrm{mg}$ ), ciprofoxacine (CIP; $30 \mathrm{mg}$ ), and chloramphenicol (CAM: $30 \mathrm{mg}$ ), all purchased from Mast Company, England.

\section{Statistical Analysis}

The data in each experiment was a representative of three independent experiments. Statistical analysis was carried out using the SPSS software (version 24.0).

\section{Ethical Considerations}

Ethical approval was obtained from the research ethics committee of selected hospitals.

\section{Results}

Bacterial Identification

Isolates which pose the following biochemical characteristics were considered Shigella: lactose negative, gas production negative, non-motile, MR positive, lysine decarboxylation negative, citrate negative, and finally, urea hydrolysis negative. According to these tests, out of 300 samples, 26 samples $(8.7 \%)$ were detected as Shigella. For species discrimination, serological typing through specific antisera against isolates was performed. Based on serotyping, it was shown that out of 26 isolates, 15 isolates ( $57.7 \%$ ) belonged to S. sonnei, and 11 isolates $(42.3 \%)$ belonged to S. flexneri (Figure 1).

\section{Antibiogram Test}

As shown in Table 1, the result of Bauer-Kirby method demonstrated that most of Shigella isolates were resistant to tetracycline $(88.46 \%)$, followed by ampicillin,

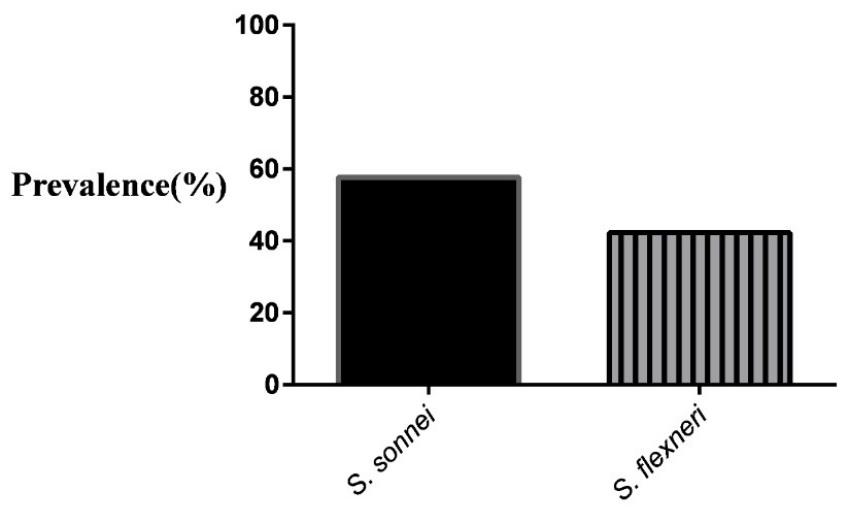

Figure 1. The Prevalence of Shigella Species Isolated From the Studied Samples. 
Table 1. Antimicrobial Susceptibility of Shigella Strains Isolated From Children

\begin{tabular}{lccc}
\hline Antimicrobial Agent & $\begin{array}{c}\text { Susceptible } \\
\text { No. } \%\end{array}$ & $\begin{array}{c}\text { Intermediate } \\
\text { No. \% }\end{array}$ & $\begin{array}{c}\text { Resistant } \\
\text { No. \% }\end{array}$ \\
\hline Ampicillin & $9(34.61)$ & $1(3.80)$ & $16(61.53)$ \\
Tetracycline & $3(11.53)$ & $0(0)$ & $23(88.46)$ \\
Co-trimoxazole & $8(30.76)$ & $2(7.69)$ & $16(61.53)$ \\
Ceftriaxone & $21(80.76)$ & $0(0)$ & $5(19.23)$ \\
Chloramphenicol & $7(36.92)$ & $3(11.53)$ & $16(61.53)$ \\
Gentamicin & $19(73.07)$ & $3(11.53)$ & $4(15.38)$ \\
Ciprofloxacin & $20(76.92)$ & $4(15.38)$ & $2(7.69)$ \\
Nalidixic acid & $14(53.84)$ & $5(19.23)$ & $7(26.92)$ \\
\hline
\end{tabular}

chloramphenicol, and Sulfamethoxazole/trimethoprim (61.53\%), while $92.30 \%$ and $85 \%$ of the isolates were sensitive or intermediate to ciprofloxacin and gentamicin, respectively.

\section{Discussion}

Shigellosis is a worldwide health problem, especially in developing countries. It is estimated that the annual morbidity rate of the infection is 80 million, which most of cases are children under 5 years old. ${ }^{2}$ Etiologically, Shigella species are the leading cause of acute diarrhea among hospitalized children (27\% of all cases). ${ }^{21}$ Different studies have shown that the prevalence of the diarrhea committed by Shigella is almost high in Iran. However, geographically the prevalence is so variable. For example, the bacterial diarrhea caused by Shigella in different cities has been as follow: Zanjan $19.6 \%,{ }^{22}$ Ahvaz $14.1 \%,{ }^{23}$ Kerman 31.6\%, ${ }^{12}$ Shahr-e-Kord $7.8 \%,{ }^{24}$ and Kashan $7.8 \% .{ }^{25}$ In Tehran, in a study by Afshari et al in summer and autumn of 2012, it was shown that $5.3 \%$ of diarrheal cases are caused by Shigella, ${ }^{21}$ and Dolatshahi et al, in another study in a period of 10 months from April to January 2015, showed that this rate was $5.16 \% .{ }^{22}$ In the present study the prevalence of the Shigella in bacterial diarrhea cases was $8.7 \%$, which the differences are not statistically significant. The prevalence of Shigella species pattern is different among developing and developed countries, while S. sonnei is the most common species in developed countries, the predominant Shigella species in developing countries is $S$. flexneri. The present study shows that the most prevalent Shigella strains in Tehran are belonged to $S$. sonnei and it is in agreement with Rahbar et al, ${ }^{26}$ Talebreza et al, ${ }^{27}$ Jafari et al, ${ }^{28}$ Tajbakhsh et al, ${ }^{29}$ Ranjbar et al, ${ }^{30}$ Eftekhari et $\mathrm{al}^{31}$ and Farshad et $\mathrm{al}^{32}$ reports. It is while in the not-too-distant past, $S$. flexneri was the most common species in $\operatorname{Tehran}^{33,34}(P<0.05)$, which indicates the improvement of hygiene level in this city. Antibiotic therapy is the choice strategy for the treatment of patient with acute Shigella infection. ${ }^{35}$ It can reduce the symptoms of disease, decrease the number of carriers, and prevent the spread of the infection. However, the irregular use of antibiotics has arisen antibiotic resistance of the bacteria and, therefore, the treatment of the infection has been complicated. ${ }^{15,32}$ Beta lactams, quinolones, and macrolides are tree classes of antibiotics which are recommended by World Health Organization (WHO) to treat the disease. The second generation of fluoroquinolones (ciprofloxacin) is now recommended by the organization as the first choice for dysentery patients resistant to thirdgeneration cephalosporins and nalidixic acid. ${ }^{2}$ However, in recent years, resistance to quinolones has been reported and it is required to update the sensitivity pattern of the species. ${ }^{36-38}$ In the present study, the highest resistance to antibiotics was observed for tetracycline, ampicillin, and chloramphenicol, while the most sensitivity was observed for gentamicin and ciprofloxacin. In a study conducted by Hossein-Pour et al, the highest antibiotic resistance to ampicillin was reported to be 89.6 percent and all cases were reported sensitive to the third generation cephalosporins and nalidixic acid, while the sensitivity to gentamicin, amikacin, and chloramphenicol was $89.8 \%, 82.5 \%$, and $69 \%$, respectively. ${ }^{35}$ Also in a study by Jamshidi et al, the highest resistance was observed for ampicillin and the highest sensitivity was seen to ciprofloxacin. ${ }^{22}$ In a study by Saadati et al., the prevalence of nalidixic acid resistant strains in Kerman was reported 9.7\%. ${ }^{18}$ Ayazi et al, in Qazvin ${ }^{36}$ and Kurdi Daryan et $\mathrm{al}^{37}$ in Isfahan reported that the prevalence of Nalidixic Acid resistant Shigella were $2 \%$ and $4 \%$, respectively. In a survey by Rahbar et al, it was observed that the most strains were resistant to ampicillin and trimethoprime/sulphamethoxazole $(88.5 \%$ and $98 \%$, respectively), whereas resistance to Chloramphenicol and Ciprofloxacin was observed to be $2.5 \%$ and $1 \%$ respectively. ${ }^{26}$ The results of the present study revealed that the prevalence of nalidixic acid-resistant Shigella strains has increased to $26.82 \%$. In agreement to some other studies, the results of the present study show that the Shigella strains have the most susceptibility to ciprofloxacin. ${ }^{39-41}$ Various reasons can lead to the dissemination of Shigella MDR strains, including easy access to antibiotics and their irregular use. ${ }^{42,43}$ Increasing Shigella resistance to antibiotics is a serious warning that should be prevented by implementing necessary measures.

\section{Conclusions}

Shigella's common species pattern has changed from S. flexneri to $S$. sonnei during the recent years in Tehran. The results of this study show that the antibiotic resistance pattern among these species is also changing, therefore, regular examination of the prevalence of different species and their drug resistance pattern is necessary to make the right decisions of the proper treatment. Indeed, increasing Shigella resistance to antibiotics is a serious warning that should be prevented by implementing necessary measures.

Authors' Contributions

All authors contributed equally to this research..

\section{Conflict of Interest Disclosures}

The authors declare they have no conflicts of interest.

\section{Acknowledgments}

Authors sincerely thank Faeze Nikukar, the head-nurse in Sina hospital, Mohammad Safaiee from Baquiyatallah University of Medical Sciences, and members of biology research center of Imam Hossain University for their kind considerations.

\section{References}

1. Cash BA, Rodo X, Emch M, Yunus M, Faruque AS, Pascual M. 
Cholera and shigellosis: different epidemiology but similar responses to climate variability. PLoS One. 2014;9(9):e107223. doi:10.1371/journal.pone.0107223.

2. World Health Organization. Guidelines for the control of shigellosis, including epidemics due to Shigella dysenteriae type 1. Geneva, Switzerland: World Health Organization; 2005.

3. Kotloff KL, Winickoff JP, Ivanoff B, et al. Global burden of Shigella infections: implications for vaccine development and implementation of control strategies. Bull World Health Organ. 1999;77(8):651-666.

4. Buzby JC. Older adults at risk of complications from microbial foodborne illness. Food Rev. 2002;25(2):30-35.

5. Khalil IA, Troeger C, Blacker BF, et al. Morbidity and mortality due to shigella and enterotoxigenic Escherichia coli diarrhoea: the Global Burden of Disease Study 1990-2016. Lancet Infect Dis. 2018. doi:10.1016/s1473-3099(18)30475-4.

6. Kramer A, Kretzschmar M, Krickeberg K. Modern infectious disease epidemiology: Concepts, methods, mathematical models, and public health. Springer; 2010. doi:10.1007/978-0-387-93835-6.

7. Bhunia AK. Shigella species. In: Foodborne Microbial Pathogens: Mechanisms and Pathogenesis. New York: Springer; 2018:331341. doi:10.1007/978-0-387-74537-4

8. Kothary MH, Babu US. Infective dose of foodborne pathogens in volunteers: a review. J Food Saf. 2001;21(1):49-68. doi:10.1111/j.1745-4565.2001.tb00307.x.

9. McCrickard LS, Crim SM, Kim S, Bowen A. Disparities in severe shigellosis among adults - Foodborne diseases active surveillance network, 2002-2014. BMC Public Health. 2018;18(1):221. doi:10.1186/s12889-018-5115-4.

10. Sur D, Ramamurthy T, Deen J, Bhattacharya SK. Shigellosis: challenges \& management issues. Indian J Med Res. 2004;120(5):454-462.

11. Ünüvar S. Microbial Foodborne Diseases. In: Foodborne Diseases. Elsevier; 2018:1-31. doi:10.1016/B978-0-12-811444-5.00001-4.

12. Hajizadeh A, Ebrahimi F, Amani J, Arpanaei A, Salmanian AH. Design and in silico analysis of pentavalent chimeric antigen against three enteropathogenic bacteria: enterotoxigenic E. coli, enterohemorragic E. coli and Shigella. Bioscience Biotechnology Research Communications. 2016;9(2):225-239.

13. Kweon MN. Shigellosis: the current status of vaccine development. Curr Opin Infect Dis. 2008;21(3):313-318. doi:10.1097/ QCO.0b013e3282f88b92.

14. Ebrahimi F, Ebadi V, Hajizadeh A, Tarverdizadeh Y, Bakhshi M. Designing a recombinant vaccine containing three bacterial proteins of EHEC, ETEC, and Shigella dysentery antigens in E. coli and evaluation of its humoral immunity in mic. J Mazandaran Univ Med Sci. 2018;27(157):1-16.

15. Christopher PR, David KV, John SM, Sankarapandian V. Antibiotic therapy for Shigella dysentery. Cochrane Database Syst Rev. 2009(4):Cd006784. doi:10.1002/14651858.CD006784.pub2.

16. Ashkenazi S, Levy I, Kazaronovski V, Samra Z. Growing antimicrobial resistance of Shigella isolates. J Antimicrob Chemother. 2003;51(2):427-429.

17. Raghunath D. Emerging antibiotic resistance in bacteria with special reference to India. J Biosci. 2008;33(4):593-603.

18. Saadati M, Setayesh MA, Hosseini SM, Akbari MR, Hosseini M, Tat $M$, Tarverdizadeh Y. "Prevalenc and antibiotic resistance pattern o shigella isolated from acute diarrheal patients in two hospitals in Kerman during 2014. Iranian Journal of Infectious Diseases and Tropical Medicine. 2015;20(70):71-76 [Persian].

19. Ranjbar R, Soltan-Dallal MM, Pourshafie MR, Mammina C. Antibiotic resistance among Shigella serogroups isolated in Tehran, Iran (2002-2004). J Infect Dev Ctries. 2009;3(8):647-648.

20. Nikkah J, Mehr-Movahead A. Antibiotic resistance among Shigella species isolated in Tehran, Iran. Ann Trop Med Parasitol. 1988;82(5):481-483

21. Afshari N, Bakhshi B, Mahmoudi aznaveh A, Fallah F, Rahbar M, Rafiei Tabatabaei S. Investigation of prevalence of Shigella sonnei in children with diarrhea admitted to two hospital Emam Khomeini and Milad in Tehran in 1391 with antimicrobial susceptibility of isolates. Iran J Med Microbiol. 2016;10(2):16-22

22. Dolatshahi Z, Amini K. Survey of tetracycline resistance genes in Shigella sonnei isolated from acute pediatric with bacterial diarrhea using Multiplex PCR method and their antibiotic resistance patterns. Zanko J Med Sci. 2016;17(52):35-44. [Persian].

23. Plotkin SL, Plotkin SA. A short history of vaccination. Vaccines. 2004;5:1-16. doi:10.1016/B978-1-4557-0090-5.00017-3.

24. Hajishengallis G, Tapping RI, Martin MH, et al. Toll-like receptor 2 mediates cellular activation by the B subunits of type II heat-labile enterotoxins. Infect Immun. 2005;73(3):1343-1349. doi:10.1128/ iai.73.3.1343-1349.2005.

25. Ahmed A, Li J, Shiloach Y, Robbins JB, Szu SC. Safety and immunogenicity of Escherichia coli O157 O-specific polysaccharide conjugate vaccine in 2-5-year-old children. J Infect Dis. 2006;193(4):515-521. doi:10.1086/499821.

26. Rahbar $M$, Deldari $M$, Hajia $M$. Changing prevalence and antibiotic susceptibility patterns of different Shigella species in Tehran, Iran. Internet J Microbiol. 2007;3(2). doi:10.5580/1761.

27. Talebreza A, Memariani M, Memariani H, Shirazi MH, Eghbali Shamsabad P, Bakhtiari M. Prevalence and antibiotic susceptibility of Shigella species isolated from pediatric patients in Tehran. Arch Pediatr Infect Dis. 2016;4(1):e32395. doi:10.5812/ pedinfect.32395.

28. Jafari F, Hamidian M, Rezadehbashi M, et al. Prevalence and antimicrobial resistance of diarrheagenic Escherichia coli and Shigella species associated with acute diarrhea in Tehran, Iran. Can J Infect Dis Med Microbiol. 2009;20(3):e56-62.

29. Tajbakhsh M, Garcia Migura L, Rahbar M, et al. Antimicrobialresistant Shigella infections from Iran: an overlooked problem? J Antimicrob Chemother. 2012;67(5):1128-1133. doi:10.1093/jac/ dks023.

30. Ranjbar R, Soltan Dallal MM, Talebi M, Pourshafie MR. Increased isolation and characterization of Shigella sonnei obtained from hospitalized children in Tehran, Iran. J Health Popul Nutr. 2008;26(4):426-430.

31. Eftekhari N, Bakhshi B, Pourshafie MR, et al. Genetic diversity of Shigella spp. and their integron content. Foodborne Pathog Dis. 2013;10(3):237-242. doi:10.1089/fpd.2012.1250.

32. Farshad S, Sheikhi R, Japoni A, Basiri E, Alborzi A. Characterization of Shigella strains in Iran by plasmid profile analysis and PCR amplification of ipa genes. J Clin Microbiol. 2006;44(8):28792883. doi:10.1128/jcm.00310-06.

33. Pourakbari B, Mamishi S, Mashoori N, et al. Frequency and antimicrobial susceptibility of Shigella species isolated in Children Medical Center Hospital, Tehran, Iran, 2001-2006. Braz J Infect Dis. 2010;14(2):153-157.

34. MoezArdalan K, Zali MR, Dallal MM, Hemami MR, SalmanzadehAhrabi S. Prevalence and pattern of antimicrobial resistance of Shigella species among patients with acute diarrhoea in Karaj, Tehran, Iran. J Health Popul Nutr. 2003;21(2):96-102.

35. Hosseinpour SS, Rahbani NM, Nikwash D. Antimicrobial resistance trends in Shigella species among patients with acute diarrhea. Medical Journal of Tabriz University of Medical Sciences. 2007;28(4):45-48. [Persian].

36. Mahyar A, Ayazi P, Kheirabi K, Sadeghi S, Daneshi-Khohan M, Javadi A. Antimicrobial resistance pattern of Shigella species isolated in children with shigellosis. Pediatr Res. 2011;70:467467.

37. Pazhani GP, Niyogi SK, Singh AK, et al. Molecular characterization of multidrug-resistant Shigella species isolated from epidemic and endemic cases of shigellosis in India. J Med Microbiol. 2008;57(Pt 7):856-863. doi:10.1099/jmm.0.2008/000521-0.

38. Rahman $\mathrm{M}$, Shoma $\mathrm{S}$, Rashid $\mathrm{H}$, et al. Increasing spectrum in antimicrobial resistance of Shigella isolates in Bangladesh: resistance to azithromycin and ceftriaxone and decreased susceptibility to ciprofloxacin. J Health Popul Nutr. 2007;25(2):158- 
167.

39. Opintan J, Newman MJ. Distribution of serogroups and serotypes of multiple drug resistant Shigella isolates. Ghana Med J. 2007;41(1):8-29.

40. Alici O, Acikgoz ZC, Gamberzade S, Gocer S, Karahocagil MK. [Antibiotic resistance rates of Shigella species isolated from stool cultures in the years 1999-2003]. Mikrobiyol Bul. 2006;40(1-2):914.

41. Gu B, Cao Y, Pan S, et al. Comparison of the prevalence and changing resistance to nalidixic acid and ciprofloxacin of Shigella between Europe-America and Asia-Africa from 1998 to 2009. Int J Antimicrob Agents. 2012;40(1):9-17. doi:10.1016/j. ijantimicag.2012.02.005.
42. Fulla N, Prado V, Duran C, Lagos R, Levine MM. Surveillance for antimicrobial resistance profiles among Shigella species isolated from a semirural community in the northern administrative area of Santiago, Chile. Am J Trop Med Hyg. 2005;72(6):851-854.

43. Dutta S, Kawamura Y, Ezaki T, Nair GB, lida K, Yoshida S. Alteration in the GyrA subunit of DNA gyrase and the ParC subunit of topoisomerase IV in Quinolone-resistant Shigella dysenteriae serotype 1 clinical isolates from Kolkata, India. Antimicrob Agents Chemother. 2005;49(4):1660-1661. doi:10.1128/aac.49.4.16601661.2005 . 